\title{
Availability of free fruits and vegetables at canteen lunch improves lunch and daily nutritional profiles: a randomised controlled trial
}

\author{
Carl K. Lachat ${ }^{1,2}$, Roosmarijn Verstraeten ${ }^{1,2}$, Bruno De Meulenaer ${ }^{1}$, Joris Menten ${ }^{3}$, Lieven F. Huybregts ${ }^{1}$, \\ John Van Camp ${ }^{1}$, Dominique Roberfroid ${ }^{2}$ and Patrick W. Kolsteren ${ }^{1,2 *}$ \\ ${ }^{1}$ Department of Food Safety and Food Quality, Faculty of Bioscience Engineering, Ghent University, 9000 Ghent, Belgium \\ ${ }^{2}$ Nutrition and Child Health Unit, Department of Public Health, Prince Leopold Institute of Tropical Medicine, Nationalestraat \\ 155, 2000 Antwerp, Belgium \\ ${ }^{3}$ Clinical Trials Unit, Prince Leopold Institute of Tropical Medicine, 2000 Antwerp, Belgium
}

(Received 26 November 2008 - Revised 29 January 2009 - Accepted 23 February 2009 - First published online 2 April 2009)

Canteens are known to be promising settings for activities to promote intake of fruits and vegetables, but it remains unclear to what extent distributing free fruits and vegetables can influence dietary patterns of customers. The present study evaluated the effect of providing fruits and vegetables for free in a university canteen on the daily diet of university canteen customers. Canteen customers ( $n$ 209) were randomly allocated to a fruit and vegetable group (FVG) and a control group (CG). FVG participants were given two portions of fruits and one portion of vegetables for free at lunchtime. Food and beverage intake was measured using a dietary record for $3 \mathrm{~d}$ and dietary quality was appraised using a comprehensive scoring system. The FVG participants ate $80 \mathrm{~g}$ more fruits $(P<0.01)$ and $108 \mathrm{~g}$ more vegetables $(P<0 \cdot 001)$ on a daily basis compared with the CG participants. No differences were found for energy density, total energy, Na and energy from fat between the groups per day. A higher intake of fruits and vegetables was observed at lunch and of vegetables during the dinner and evening snacks. The FVG participants were more likely to comply with dietary recommendations for fruits and vegetables and had a better dietary profile on the study days and for the lunch consumed on those days. The results of the present study demonstrate how modifications of a canteen lunch can be instrumental to enhance the nutritional quality of lunch as well as the overall quality of the diet of the customers.

Canteen lunch: Young adults: Fruit: Vegetables: Diet quality

Adequate consumption of fruits and vegetables, an essential element of a healthy diet ${ }^{(1)}$, is one of the most prevailing public health challenges in Europe ${ }^{(2)}$. In Belgium for instance, food-based dietary guidelines specify that daily fruit consumption should be at least $250 \mathrm{~g}$ and vegetables $300 \mathrm{~g}$ per day ${ }^{(3)}$. However, with an average daily consumption of 118 and $138 \mathrm{~g}$ of fruits and vegetables, respectively, intake remains insufficient $^{(4)}$.

Increased fruit and vegetable consumption is considered a potential strategy to prevent weight gain or reduce obesity ${ }^{(5)}$. Important driver implicated in this process is a reduction of energy density and total energy intake. To increase fruit and vegetable consumption, various strategies are possible. First, a review showed that strategies to encourage consumers to eat more fruits and vegetables generally have a positive effect ${ }^{(6)}$. The epidemiological evidence mainly originates from cross-sectional studies or interventions that have used dietary advice or counselling ${ }^{(7,8)}$. Second, the provision of free fruits and vegetables has also generally shown promising effects. Children in schools receiving free fruit increased their consumption of fruit ${ }^{(9-12)}$. After 3 years of implementation, the effects were still observed in Norway ${ }^{(11)}$. The European
Commission has recently launched a proposal to establish a European free fruit and vegetable programme for school children ${ }^{(13)}$. However, it remains unclear how giving free fruits and vegetables has affected the overall diet. The effect of such interventions in adults is also poorly documented.

In Belgium, many university students eat in canteens. When eating out, customers do not have the same level of control over what is eaten compared with eating foods prepared at home ${ }^{(14)}$. Limited nutritional information on the meal choices is provided, and customers have little or no influence on the composition and ingredients of food offered out of home. We previously demonstrated how the nutritional profile of the food consumed in a university canteen is largely determined by what is offered and how fruits and vegetables are lacking in the meals ${ }^{(15)}$. The relationship between the nutritional profile of what is offered when eating out of home and what is consumed offers a window of opportunity to improve diets. In this regard, worksite and university canteens are appropriate settings to improve diets of a large number of consumers $^{(6,16)}$. It was shown previously how eating in a canteen can ensure compliance with recommended dietary habits in Finland ${ }^{(17)}$. Although distributing free fruits and vegetables 
has a number of operational and logistic advantages compared with other interventions to encourage healthy eating, it is so far unknown how it can influence by itself the dietary patterns of adult customers.

\section{Objective}

The objective of the present study was to evaluate the effect of giving free fruits and vegetables during the lunch on fruit, vegetables, energy, fat and $\mathrm{Na}$ intake during the lunch and over the day.

\section{Methodology}

The present study took place in December 2005 in the canteen of the Faculty of Bioscience Engineering at Ghent University, Belgium, where the meal composition had already been studied in a previous study ${ }^{(15)}$. The present study was a randomised controlled intervention trial. Participants were regular (i.e. at least three meals a week) customers of a university canteen, essentially students and university staff. Participants were explained the overall research procedures but were blinded to the trial objectives. All participants provided written consent before the study and were rewarded with two cinema tickets.

Sample size was calculated using Gpower $3^{(18)}$ procedures for a priori differences of two independent means. We took the mean of fruit $(111.4$ (SD 76.9) $\mathrm{g}$ ) and vegetable $(141.3$ $(\mathrm{SD} 50 \cdot 9) \mathrm{g}$ ) intake of Belgian adults ${ }^{(4)}$ to calculate the sample size needed for the study. The sample size needed to detect a difference of half a portion size of fruit was sixtyeight per group with a precision of $5 \%$ and a power of $85 \%$. At least thirty-one participants per group were needed to demonstrate such difference for vegetables. To compensate for dropout and exclusions for over- and underreporting recordings, we envisaged an initial sample size of 100 participants per group.

Participants were randomly allocated to a fruit and vegetable group (FVG) or a control group (CG) using a computer-generated list of random numbers. The intervention started 1 month after the registration. They did not know to which group they were allocated before their first canteen visit. Participants were asked to eat a hot lunch in the canteen for $3 \mathrm{~d}$, which could be chosen freely over a 3-week study period. On their days of eating in the canteen, the FVG participants presented themselves at a registration desk and were offered a salad and two free portions of fruit. The set-up of the study was done to minimise the influence of the fruit and vegetable distribution on the food intake of canteen customers other than the FVG participants. The distribution of fruits and vegetables took place in a separate place outside the area where normal canteen food is served and paid for. One portion of fruit was either one apple $(155 \mathrm{~g})$, two mandarins $(90 \mathrm{~g})$ or one pear $(170 \mathrm{~g})$. Three different types of salads were available: a tomato salad $(200 \mathrm{~g})$; a four-season salad with mainly cabbage (170 g); a cucumber salad (200 g). The fruits and vegetables were seasonal and similar to those sold in the canteen. Participants could refuse the food and freely combine the portions of different fruits and vegetables. Vegetable portions contained no seasoning or salt, were pre-packed, ready-to-eat and easy to transport for later consumption. The FVG and CG participants paid for their meals like regular customers.

The food and beverage consumption was monitored by a self-administered $3 \mathrm{~d}$ dietary record, an appropriate method to estimate absolute intake of food, energy and macronutrients ${ }^{(19)}$. Participants completed the forms only during the days in which they took lunch in the canteen. The dietary record included instructions and examples on how to complete the form and a short introduction was given by the researchers to each participant when they collected the registration forms. Sex, date of birth, height and weight were self-reported on the same form to minimise the survey burden. Only weekdays were included in the dietary record as no lunch was provided in the canteen during weekend days. Participants were also asked to record all physical activities with registrations per $15 \mathrm{~min}$ and food or drinks consumed during $24 \mathrm{~h}$. The activities reported were multiplied with their respective metabolic equivalent coefficient ${ }^{(20)}$ and summed to obtain an individual estimation of energy expenditure (EE) for $24 \mathrm{~h}$. The $15 \mathrm{~min}$ diary of activities was validated previously as an epidemiological instrument to estimate $\mathrm{EE}^{(21)}$. The $3 \mathrm{~d}$ dietary and physical activity registrations were averaged to obtain a measure per day. Participants were considered underreporting when their average intake was below $3 \mathrm{SD}$ of their average EE and overreporting when energy intake was more than $3 \mathrm{SD}$ of their EE. Over- and underreporting subjects were excluded from analysis. Physical activity data were entered in Epidata version 3.1 (EpiData Association, Odense, Denmark).

Each of the meal choices on the menu served in the canteen was purchased at least twice to obtain samples of the food. Portion sizes were weighed up to $1 \mathrm{~g}$ using a digital kitchen balance (type Phillips HR 2389 and HR 2393). Samples of the meal components were frozen before laboratory analysis. The portion sizes of food other than the canteen lunch were obtained from the dietary record or from using standardised portion sizes for Belgian food items ${ }^{(22)}$. The registration form contained instructions to specify the portion sizes using common household measurement. Respondents were also asked to report the quantities for commercial products when available. When submitting, the forms were reviewed by the researchers, and respondents were asked for more details where necessary. The forms also contained the email address of the respondents so they could be contacted later for more information.

Fat content was obtained after acid dissolution and subsequent Soxhlet extraction ${ }^{(23)}$. Crude protein content was determined according to the Kjeldahl method (Association of Official Analytical Chemists method 920.87) ${ }^{(24)}$ and using a conversion factor of $6 \cdot 25$. For the Kjeldahl analysis, a 2020 Digestor and a 2200 Kjeltec Auto distillation unit from Foss Tecator (Hillerød, Denmark) were used. DM content was obtained after mixing the homogenised sample with dried sea sand and drying at $105^{\circ} \mathrm{C}$ until the weight remained constant according to the Association of Official Analytical Chemists method $984 \cdot 25^{(24)}$. The carbohydrate content was calculated by difference (carbohydrate $=100-$ (water + protein + fat + ash $)$ ). Energy content was calculated using Atwater conversion factors, which are believed to be appropriate for low-fat or non-high-fibre diets ${ }^{(25)}$. The analyses were carried out in double and the average value of these two measurements was used. In total, forty-five meal components 
were analysed thereby covering the overall offer in the canteen. The Na content of food served in the canteen was obtained from the technical files supplied by the producers contracted by the university.

The nutrient content of foods that were not served as part of the canteen lunch were obtained from the Belgian food composition table $\mathrm{e}^{(26,27)}$. When data were not available from these sources, nutrient composition was completed using United States Department of Agriculture data from ESHA Food Processor version 8.4.0 (ESHA Research, Salem, OR, USA) or from nutrient information on the food labels. Food intake data were processed using a format designed in MS Access. Potatoes were considered as a carbohydrate source and thus not included in the vegetable fraction of the meals. A serving size of fruits and vegetables was defined as $80 \mathrm{~g}$ following the recommendations by the World Cancer Research Fund ${ }^{(28)}$

We compared average intake per day and for different eating moments during the day.

Six eating moments were arbitrarily defined for this purpose, namely: breakfast (from 06.00 to 09.00 hours); morning snack (from 09.00 to 11.00 hours); lunch (from 11.00 to 14.00 hours); afternoon snack (from 14.00 to 17.00 hours); dinner (from 17.00 to 20.00 hours); evening snacks (20.00 until 06.00 hours).

We developed a score to evaluate the dietary quality of food taken at lunch and on a daily basis. In Belgium, it is recommended that a diet should provide daily less than $35 \%$ of energy from fat, less than $3500 \mathrm{mg}$ of $\mathrm{Na}$ and a total amount of fruits and vegetables of at least $550 \mathrm{~g}^{(29)}$. For this purpose, a cumulative score was constructed where one point was awarded if the average daily diet complied with one of the Belgian recommendations. We used a similar approach to evaluate the lunch quality using following criteria: the lunch contains maximum $2000 \mathrm{mg}$ of $\mathrm{Na}$; less than $35 \%$ of the energy is supplied by fat; at least $200 \mathrm{~g}$ of fruits or vegetables. The rationale for using these criteria to evaluate lunches was reported earlier ${ }^{(15)}$

Data analysis was by intention-to-treat. Data on both food consumption and physical activity were analysed by the statistical package Stata (Intercooled Stata version10 Statacorp, College Station, TX, USA). In case of severe departure from normality, data were transformed using a logarithmic transformation. Differences in mean intake between FVG and CG were assessed using a $t$ test. Logistic and ordinal logistic regressions were used to compare odds of complying with dietary recommendations between intervention and CG. Differences in the consumption of fruits and vegetables between the study days were calculated using multilevel analysis. EE and sex were included as covariates in the logistic and ordinal regression models. Proportionality of odds for the ordinal regression was tested using the likelihood-ratio test. A Bonferroni correction was applied when carrying out multiple testing of differences in fruit and vegetable intake at different meal moments. Results are presented as arithmetic means and standard deviations. A 95\% CI is reported for differences in fruit and vegetable between the FVG and the $\mathrm{CG}$ and was calculated from the non-transformed variables. The significance level was set at $5 \%$ for all analyses and all tests were two-sided.

A proportion of participants did not provide any data form. Sensitivity analysis was used to explore the impact of missing data on the results. We simulated various scenarios in which these participants would have a specific dietary pattern, BMI or EE. Food intake of these participants was replaced by the mean dietary intake of subjects in their group that had a low, mean or high intake of energy. The low, middle and high consumption were defined using quartiles: the low consumers were the first quartile; the middle consumers were the two middle quartiles; the high consumers were the high quartile of daily energy intake. We used the same approach for intakes of total fruit and vegetable, BMI and EE and carried out a total of twelve scenarios. All $P$ values were corrected for multiple testing.

\section{Results}

General

From the 209 people who registered for the study, $76 \%$ completed and submitted forms (Fig. 1). The response rates for the FVG and the CG were 83 and $70 \%$, respectively, and were not significantly different between both groups $(P=0.08)$. No participants were classified as underreporting and three were considered overreporting. There were no differences between the FVG and the CG in prevalence of overreporting $(P=0.66)$. Four days from four respondents were excluded because of incomplete registrations for those days. The average of the two remaining days was used for those individuals.

Table 1 shows the general characteristics of the participants. Of the participants, $64 \%$ were female. There was no difference in sex distribution between the CG and the FVG $(P=0.82)$. Of the participants, $5 \cdot 8 \%$ were overweight $\left(B M I \geq 25 \cdot 0 \mathrm{~kg} / \mathrm{m}^{2}\right)$. This proportion was not different between the FVG and the CG $(P=0.92)$. None of the participants was obese.

\section{Fruit and vegetable intake}

On average, 241 (SD 42) $\mathrm{g}$ of fruit and 175 (SD 39) $\mathrm{g}$ of vegetables were distributed to the FVG participants per day. This quantity corresponds to 3.0 servings of fruit and 2.2 servings of vegetables. On a daily basis, 33, 20 and $47 \%$ of the fruit portions distributed were apples, pears and mandarins,

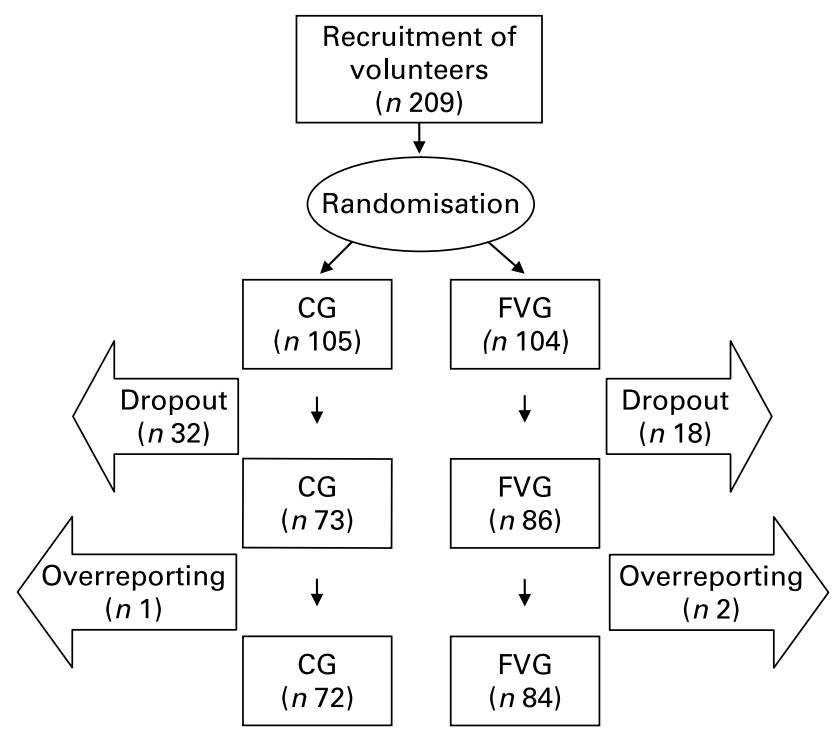

Fig. 1. Study design. CG, control group; FVG, fruit and vegetable group. 
Table 1. General characteristics from the study population

(Arithmetic means and standard deviations)

\begin{tabular}{|c|c|c|c|c|c|c|}
\hline & \multicolumn{2}{|c|}{ All $(n 156)$} & \multicolumn{2}{|c|}{ CG $(n 72)$} & \multicolumn{2}{|c|}{ FVG $(n 84)$} \\
\hline & Mean & SD & Mean & SD & Mean & SD \\
\hline Age (years) & $22 \cdot 8$ & 3.5 & $22 \cdot 7$ & 3.5 & 23.0 & 3.4 \\
\hline BMI $\left(\mathrm{kg} / \mathrm{m}^{2}\right)^{\star}$ & 21.5 & $2 \cdot 1$ & $21 \cdot 3$ & $2 \cdot 1$ & 21.6 & $2 \cdot 1$ \\
\hline Energy expenditure $(\mathrm{kJ}) \dagger$ & $10727 \cdot 8$ & $1949 \cdot 7$ & 10786.4 & $2025 \cdot 1$ & 10677.6 & 1899.5 \\
\hline
\end{tabular}

CG, control group; FVG, fruit and vegetable group.

${ }^{\star} \mathrm{BMI}$ was calculated from self-reported weight and height.

$\dagger$ Energy expenditure was estimated from diary recordings.

respectively. The majority $(57 \%)$ of vegetable portions distributed were tomatoes, while four-season and cucumber salads were taken in, respectively, 20 and $23 \%$ of the cases.

The FVG consumed $79.9 \mathrm{~g}(12.0,147.9)$ of fruit and $107.7 \mathrm{~g}$ $(63.5,151.9)$ of vegetables more compared with the CG on average on a daily basis (Table 2). The difference in fruit and vegetable intake corresponds to 1.0 and 1.3 servings, respectively. The extra fruits and vegetables provided an additional $140.2 \mathrm{~kJ}(33.5 \mathrm{kcal})$ and $173.6 \mathrm{~kJ}(41.5 \mathrm{kcal})$, respectively.

Subjects from the FVG ate more fruits and vegetables, particularly at lunch (Figs. 2 and 3). During lunch, participants in the FVG had an average consumption of $70 \cdot 4 \mathrm{~g}(57.9,83.0)$ of fruits and $240.0 \mathrm{~g}(214.3,265.7)$ of vegetables. They consumed $35.8 \mathrm{~g}(18.3,53 \cdot 2)$ of fruits and $49.2 \mathrm{~g}(14.7,83.6)$ vegetables more than the $C G$ during lunch on a daily basis. The higher intake of vegetables was also observed during dinner and evening snack. Before the lunch, no significant differences were observed in both fruit and vegetable intake. The energy content $(P=0.56)$, energy density $(P=0.65)$, energy from fat $(P=0.69)$ and weight of the food $(P=0 \cdot 12)$ of the lunch were not different between the CG and the FVG.

There were no differences in the number of servings of fruits and vegetables distributed over the study days $(P=1.00$ and 0.39 , respectively). No differences were observed for the average intake of fruit over the study days $(P=0.49)$ in the FVG. The vegetable intake of the FVG, however, decreased over the days of study $(P=0.047)$ with a notable decline after the first day.

\section{Quality of the lunch and daily diet}

On average, $57 \%$ of the CG and $82 \%$ of the FVG consumed the recommended $200 \mathrm{~g}$ of fruits and vegetables at lunch. On a daily basis, $42 \%$ of the CG and $76 \%$ of the FVG consumed the recommended $400 \mathrm{~g}$ of fruits and vegetables. More lunches consumed by the FVG participants complied with a higher quality score for lunch compared with the CG (Fig. 4). Lunches consumed by the FVG participants were four times more likely to contain at least $200 \mathrm{~g}$ fruits and vegetables and were three times more likely to comply with an additional recommendation for a lunch (Table 3).

With regard to daily dietary recommendations, the FVG participants were more likely to meet the recommendations for fruits and vegetables but not for the energy from fat and $\mathrm{Na}$ (Table 4). Subjects in the FVG were twice more likely to have had a daily diet with a higher quality score. Fig. 5 illustrates how more participants of the FVG had a diet with a higher quality score compared with the CG. Including the overreporting individuals did not change the findings of the study and had no effect on the significance of the tests.

\section{Sensitivity analysis}

In all scenarios, the FVG participants consumed more fruits and vegetables than the CG $(P<0.05)$. The mean difference ranged from $61.7 \mathrm{~g}(1.1,122.2)$ to $120.3 \mathrm{~g}(63.6,177.0)$ for fruit and from $85.4 \mathrm{~g}(48.1,122.6)$ to $117.4 \mathrm{~g}(80.6,154.1)$ for vegetables. In all but two scenarios, the difference of intake of both fruits and vegetables was significant $(P<0.05)$. In the scenario in which the defaulters all had a very high energy intake or high intake of fruits and vegetables, only the difference of vegetable intake reached statistical significance. In all scenarios, the mean energy intake, weight of food consumed, energy density, energy from fat and $\mathrm{Na}$ were not significantly different between the FVG and CG.

Table 2. Characteristics of the average dietary intake over the $3 \mathrm{~d}$ of measurement

(Arithmetic means and standard deviations)

\begin{tabular}{|c|c|c|c|c|c|c|c|}
\hline & \multicolumn{2}{|c|}{ All (n 156) } & \multicolumn{2}{|c|}{$\mathrm{CG}(n 72)$} & \multicolumn{2}{|c|}{ FVG $(n 84)$} & \multirow[b]{2}{*}{$P$} \\
\hline & Mean & SD & Mean & SD & Mean & SD & \\
\hline Fruit (g) & 319 & 217 & 276 & 218 & 356 & 211 & 0.003 \\
\hline Vegetables (g) & 326 & 149 & 268 & 128 & 376 & 148 & $<0.001$ \\
\hline Energy intake (kJ) & 9891 & 2180 & 9966 & 2259 & 9824 & 2117 & 0.69 \\
\hline Weight of food consumed (g) & 2879 & 741 & 2827 & 672 & 2923 & 797 & 0.27 \\
\hline Energy density (kJ/100 g) & 355.6 & 79.5 & 363.2 & 79.5 & 348.9 & 79.5 & 0.49 \\
\hline Energy from fat (\%) & 35 & 6 & 35 & 5 & 36 & 6 & 0.42 \\
\hline $\mathrm{Na}(\mathrm{mg})$ & 1995 & 685 & 2035 & 754 & 1960 & 623 & 0.70 \\
\hline
\end{tabular}

$\mathrm{CG}$, control group; FVG, fruit and vegetable group. 


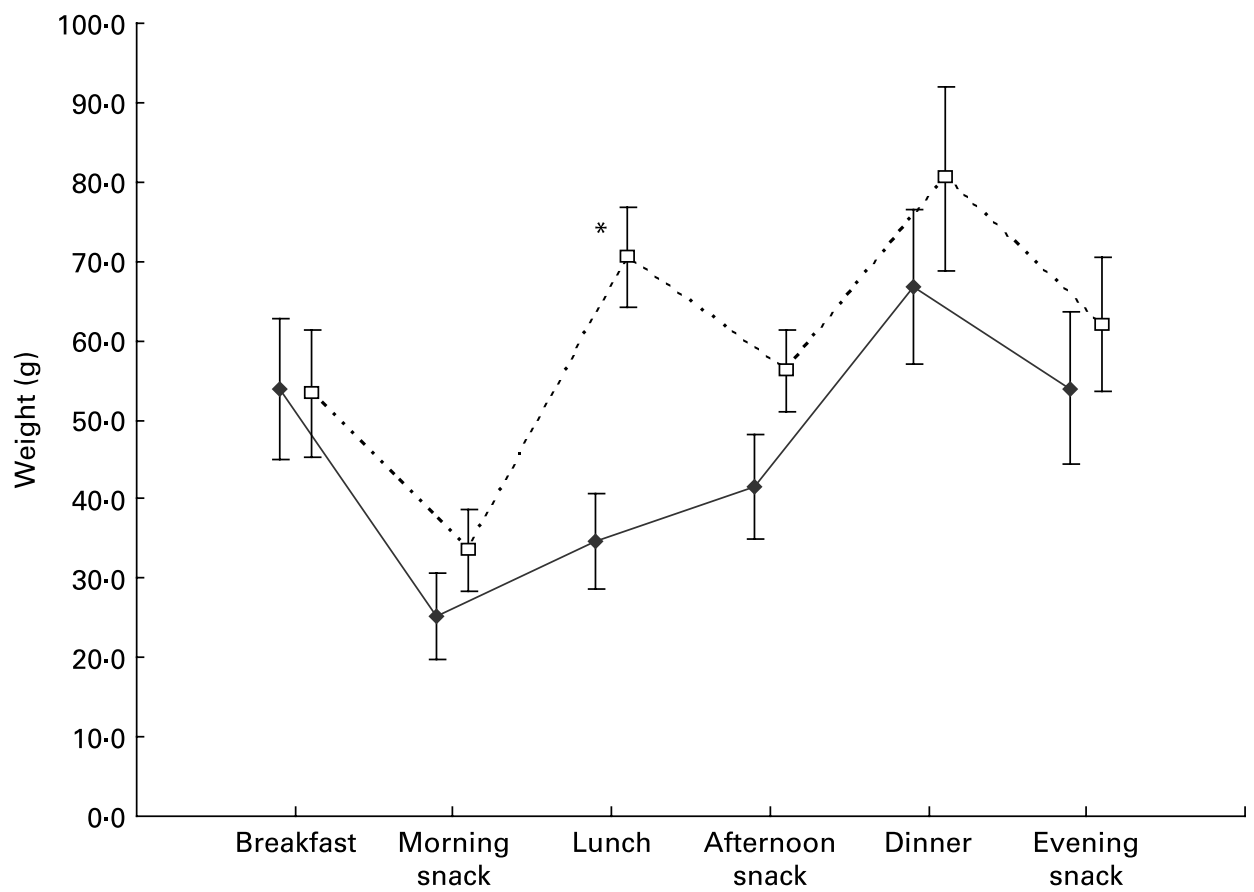

Fig. 2. Average consumption of fruit in different meal moments per day $(n 156$, arithmetic means and $95 \% \mathrm{Cl}) .{ }^{*} P<0.05$, Bonferroni corrections applied. $\bullet$, Control group; $\square$, fruit and vegetable group.

\section{Discussion}

Providing free fruits and vegetables at lunch lead to higher intakes of both fruits and vegetables. In this regard, it improved the dietary quality of both the lunch and the diet on a daily basis. We provided a rather large portion of fruits and vegetables at lunch. Expectedly, this quantity was not consumed entirely at lunch. The added fruits and vegetables lead to an increased consumption of $36 \mathrm{~g}$ of fruits and $49 \mathrm{~g}$ vegetables during lunch. On average, the total quantity of fruits and vegetables consumed during lunch by the FVG was 70.4 and $240.0 \mathrm{~g}$, respectively. Given the very large quantities of fruits and vegetables distributed, it seems very likely that the amount of fruits and vegetables consumed by the FVG participants approaches the upper limit of what one can expect as a reasonable maximum consumption during a hot lunch.

The increase in vegetable consumption we saw over the daily diet is due to the fact that they were presented in separate containers to transport the food for later consumption. This is not a usual way of presenting vegetables in a lunch.

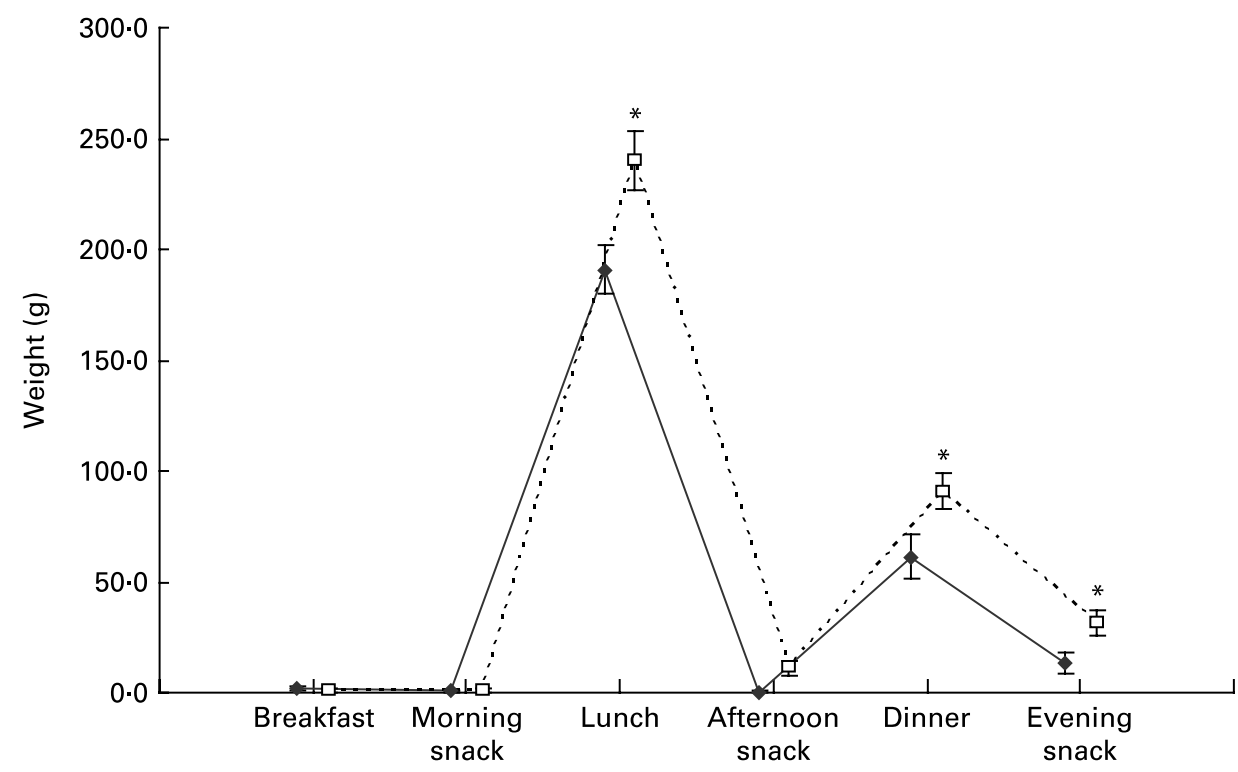

Fig. 3. Average consumption of vegetables in different meal moments per day $(n 156$, arithmetic means and $95 \% \mathrm{Cl})$. ${ }^{*} P<0.05$, Bonferroni corrections applied. $\bullet$, Control group; $\square$, fruit and vegetable group. 


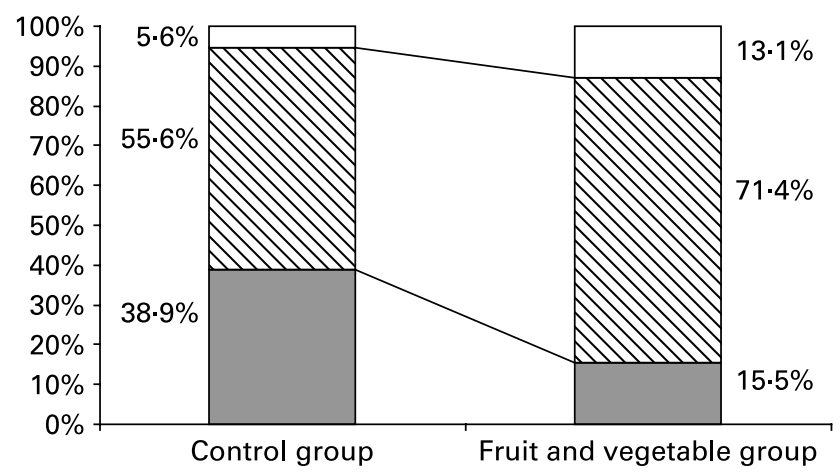

Fig. 4. Percentage of lunches consumed that comply with a combination of three recommendations ( $n$ 156). Recommendations used here are: lunch content $<2000 \mathrm{mg}$ of $\mathrm{Na} ;<35 \%$ of the energy from fat; $>200 \mathrm{~g}$ of fruits and vegetables. $\mathbb{\nabla}$, Complying with one recommendation; $\square$, complying with two recommendations; $\square$, complying with three recommendations.

Interventions aiming to increase vegetable intake should take into account a ceiling effect per meal type, as demonstrated in the present study. The observed increase in fruit consumption per day is a more reproducible effect. Fruit comes in natural containers and what is not consumed at lunch can be taken for later consumption. Providing extra fruit at lunch can therefore increase daily fruit consumption considerably.

We did not observe differences in energy intake, total weight of the food or energy density between the present intervention and CG during the lunch or on a daily basis. The fruits and vegetables distributed did not significantly displace other foods to affect energy content of the overall daily diet.

Almost half of the increase in fruits and vegetables distributed was observed after lunch time. Fruit is known to be suitable for consumption as snacks. Increasing vegetable consumption, however, remains quite challenging ${ }^{(6)}$. Supplying the vegetables in a takeaway form was a factor contributing to the considerable increase in consumption in the present study. The additional vegetables were quite a large additional portion. Since they were ready to eat and packed in plastic containers, it was convenient to consume them at a later moment during the day.

Study participants of the FVG did not lower their fruit and vegetable intake significantly before lunch in anticipation of the distributions. Since participants could chose the days in

Table 3. Compliance with different lunch recommendations when being part of the fruit and vegetable group

(Odds ratios and $95 \%$ confidence intervals)

\begin{tabular}{lccc}
\hline Recommendations & OR $(n 156)$ & $95 \% \mathrm{Cl}$ & $P$ \\
\hline $\begin{array}{l}\text { The lunch contains at least } 200 \mathrm{~g} \\
\text { of fruits and vegetables }\end{array}$ & 3.7 & $1.8,7.8$ & $<0.001$ \\
$\begin{array}{l}\text { Less than } 35 \% \text { of energy } \\
\text { originated from fat in the lunch }\end{array}$ & 1.7 & $0.6,4.5$ & 0.30 \\
$\begin{array}{l}\text { The lunch contains less } \\
\text { than } 2000 \mathrm{mg} \mathrm{Na}^{*}\end{array}$ & - & - & - \\
\begin{tabular}{l} 
Quality score for lunch $\dagger$ \\
\hline
\end{tabular} & 3.3 & $1.7,6.6$ & $<0.001$ \\
\hline
\end{tabular}

OR with the control group as a reference. Models were adjusted for energy expenditure (calculated from a diary) and sex.

${ }^{*}$ None of the lunches had a Na content $>2000 \mathrm{mg}$.

†Cumulative score of at least $200 \mathrm{~g}$ of fruits and vegetables, $<35 \%$ energy originated from fat and $<2000 \mathrm{mg} \mathrm{Na}$ in the lunch.
Table 4. Compliance with different daily dietary recommendations when being part of the fruit and vegetable group

(Odds ratios and $95 \%$ confidence intervals)

\begin{tabular}{lccc}
\hline Recommendations & OR $(n$ 156) & $95 \% \mathrm{Cl}$ & $P$ \\
\hline $\begin{array}{l}\text { Consumption of at least } 300 \mathrm{~g} \\
\quad \text { of fruit per day }\end{array}$ & 1.9 & $1.0,3.7$ & 0.047 \\
$\begin{array}{l}\text { Consumption of at least } 250 \mathrm{~g} \\
\quad \text { of vegetables per day }\end{array}$ & 4.4 & $2.2,9.0$ & $<0.001$ \\
$\begin{array}{l}\text { Consumption of at least } 550 \mathrm{~g} \text { of } \\
\quad \text { fruits and vegetables per day }\end{array}$ & 4.6 & $2.3,9.2$ & $<0.001$ \\
$\begin{array}{l}\text { Less than 35\% of energy from } \\
\quad \text { fat is supplied by the daily }\end{array}$ & 0.6 & $0.3,1.1$ & 0.09 \\
$\begin{array}{l}\text { The daily diet contains less } \\
\quad \text { than 3500 mg Na }\end{array}$ & 2.3 & $0.4,13.4$ & 0.34 \\
\begin{tabular}{l} 
Quality score for daily diet* \\
\hline
\end{tabular} & 2.0 & $1.1,3.7$ & 0.02 \\
\hline
\end{tabular}

OR with the control group as a reference. Models were adjusted for energy expenditure (calculated from a diary) and sex.

* Cumulative score of at least $550 \mathrm{~g}$ of fruit and vegetables, $<35 \%$ energy from fat and $<3500 \mathrm{mg}$ Na per day.

which they had lunch in the canteen freely, it was interesting to look at this specifically.

We observed a decrease in the average amount of vegetables consumed by FVG participants, in particular after the first day. The average consumption of fruit was not different between the study days. The set-up of the present study does not allow us to assess the reasons for this however and further studies are needed to confirm this observation.

The present study was exploratory. Although not significantly different, the attrition rate was higher in the CG compared with the intervention group. Participants that dropped out of the study did not submit their forms and, as all the information was reported on those forms, we consequently had no information to compare them with those that completed the study. Although the lack of baseline information on the defaulters is a limitation of the study, the outcome of the sensitivity analysis shows that our findings are very robust.

The strength of the present study is the careful follow-up of participants for food consumption, monitoring of physical activities and composition of foods consumed in the canteen. Although we tried to minimise the influence of the intervention on knowledge and awareness of canteen customers with

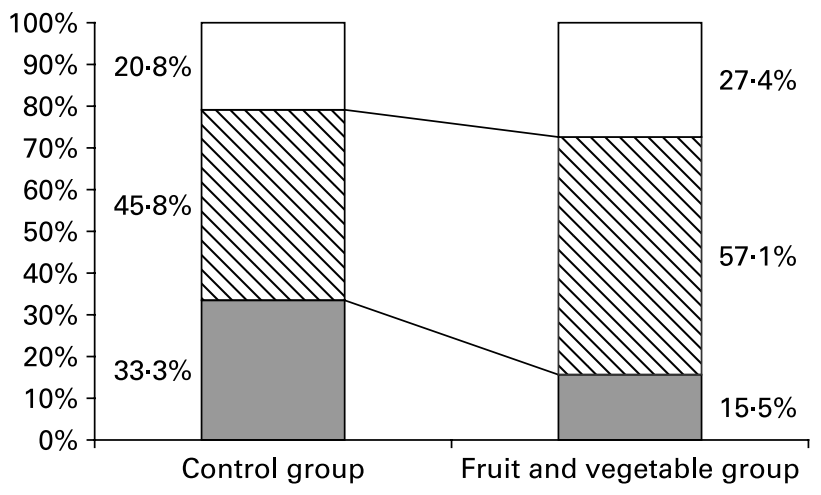

Fig. 5. Percentage of customers with a daily diet complying with a combination of three recommendations ( $n$ 156). Recommendations used here are the daily diet supplies less than $35 \%$ energy from fat; contains at least $550 \mathrm{~g}$

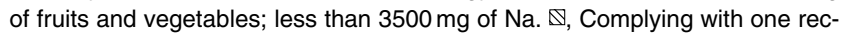
ommendation; $\square$, complying with two recommendations; $\square$, complying with three recommendations. 
regard to eating fruits and vegetables or healthy eating in general, we cannot rule out a possible influence of our presence at the registration desk, the distribution of fruits and vegetables and explanations on the registrations on the food consumption of the intervention group.

Though the lack of clear descriptions of what is defined as a serving size in various papers hampers comparing the results of studies, the positive effect of our intervention on fruit and vegetable intake is generally consistent with other studies. A review of interventions aiming to increase fruit and vegetable intake reported effect sizes of $0 \cdot 1-1.4$ servings per day ${ }^{(6)}$. The present review considered only interventions lasting for at least 3 months. French and stables reported an increase of $0 \cdot 2-0 \cdot 6$ servings of fruit for environmental interventions to promote fruit and vegetable consumption in youths in school settings ${ }^{(30)}$. An increase of $70 \mathrm{~g}$ of fruits and vegetables per customer was reported for a worksite fruit and vegetable intervention $^{(16)}$. Our findings are generally higher compared with these studies. Arguably, the short-term character of our evaluation and the direct effect of providing food for free may explain this.

The cost-effectiveness of freely distributing fruits and vegetables is an important issue $\mathrm{e}^{(9,11)}$. We applied an ad libitum principle and distributed large portions of fruits and vegetables. In this best-case scenario, all choices of fruits and vegetables were always available to the FVG participants. Doing so, the distribution of fruits and vegetables in the present study almost doubled the price of the lunch for FVG participants. The total production cost of a meal is about $5-10 €$ per meal, depending on the dish. The total cost of the fruits and vegetables distributed was $4 \cdot 27 €$ per FVG participant per day. This cost includes those fruits and vegetables that were discarded when expiry dates were passed. The real increase in fruit and vegetable intake, however, accounts only for just a share of the total cost of the fruit and vegetable distribution. Distributing one serving of fruit and 1.3 servings of vegetables would reduce the cost to $3.30 €$ per FVG participant per day. The main aim of the present study, however, was to evaluate the nutritional implication of distributing fruits and vegetables. We consequently did not aim to establish costeffectiveness of such intervention and did not try to minimise the cost of the intervention.

The intervention also resulted in a 30 and $181 \mathrm{mg}$ reduction in $\mathrm{Na}$ intake at lunch and dinner, respectively. Although total $\mathrm{Na}$ intake per day did not differ between the groups and individuals in the FVG were not more likely to meet dietary recommendations, the effect of the intervention on salt intake is noteworthy. Surprisingly, none of the lunches had a $\mathrm{Na}$ content $>2000 \mathrm{mg}$, which is in contrast with what we previously reported ${ }^{(15)}$. In the canteen, salt portions are available for free and account for a large share of the $\mathrm{Na}$ intake during the lunch. Most likely, participants did not report accurately those extra salt portions taken during the canteen lunch.

We demonstrated how the extra fruits and vegetables improved the overall daily diet in a qualitative way. The percentages of customers complying with a single dietary recommendation for lunch or a daily diet decreased considerably. Participants of the FVG were almost five times as likely to meet daily recommendations for fruit and vegetable intake. The results of the present study demonstrate how modifications of a canteen lunch can be instrumental in changing the daily diet of customers. Traditionally, workplace-based interventions to improve fruit and vegetable consumption are multifaceted and comprehensive $\mathrm{e}^{(6,31)}$. We documented the effect of an intervention that increased the availability and accessibility of fruits and vegetables. We built our intervention on modification of food supplied in the canteen. Doing so, customers were stimulated to increase their consumption of fruit of vegetables, without specific activities to increase knowledge or awareness on the benefits of consuming fruits and vegetables. In the past, various studies have demonstrated how school-based awareness and education interventions can be instrumental to increase fruit and vegetable consumption ${ }^{(6)}$. The present study adds evidence to consider additional environmental modifications in food served in a canteen to consolidate the effectiveness of interventions aiming to modify food intake of canteen customers.

The present results provide valuable grounds to encourage the involvement of the catering sector more in public health policies. The findings also pave the way for further intervention studies in restaurants and other private food outlet settings, for which the evidence base for health promotion interventions is still poorly developed.

\section{Acknowledgements}

The authors wish to thank Mr Philiep Denis, the canteen staff and student administration of the Faculty of Bioscience Engineering for their cooperation during the data collection. Special credits go to the students of the Master course in Nutrition and Rural Development of 2005-2006 for their enthusiasm during data collection. None of the authors declare any conflict of interest. The present research received no specific grant from any funding agency in the public, commercial or notfor-profit sectors. The present study was conducted according to the guidelines laid down in the Declaration of Helsinki. Written informed consent was obtained from all subjects. Author contributions. C. K. L. and P. W. K. designed and carried out the study. C. K. L. drafted the manuscript. C. K. L., P. W. K., L. F. H., J. M., D. R. and R. V. carried out data entry and analysis. B. D. M. and J. V. C. supervised laboratory analysis of food samples. All authors critically revised the drafted manuscript.

\section{References}

1. Van Duyn MS \& Pivonka E (2000) Overview of the health benefits of fruit and vegetable consumption for the dietetics professional: selected literature. J Am Diet Assoc 100, 1511-1521.

2. Kafatos A \& Codrington CA (2004) Eurodiet Core Report, Nutrition and Diet for Healthy Lifestyles in Europe. Science and Policy Implications. Crete: University of Crete, School of Medicine and European Commission DG Sanco.

3. VIG (2003) : Vlaams instituut voor Gezondheidspromotie.

4. Scientific Institute of Public Health. De Belgische Voedselconsumptiepeiling 1 -2004: Synthese [The Belgian Food Consumption Survey 1: Synthesis]. Devriese S, Huybrechts IMM \& Van Oyen H, editors. [D//2505/17, IPH/EPI REPORTS No 2006 - 017]. 2006. Brussels, Scientific Institute of Public Health.

5. WHO [Branca F, Nikogosian $\mathrm{H}$ \& Lobstein $\mathrm{T}$, editors]. The Challenge of Obesity in The WHO European Region and The Strategies for Response. Copenhagen: World Health Organization Regional Office for Europe. 
6. Pomerleau J, Lock K, Knai C, et al. (2005) Interventions designed to increase adult fruit and vegetable intake can be effective: a systematic review of the literature. J Nutr 135, 2486-2495.

7. Rolls BJ, Ello-Martin JA \& Tohill BC (2004) What can intervention studies tell us about the relationship between fruit and vegetable consumption and weight management? Nutr Rev 62, 1-17.

8. Tohill BC, Seymour J, Serdula M, et al. (2004) What epidemiologic studies tell us about the relationship between fruit and vegetable consumption and body weight. Nutr Rev 62, 365-374.

9. Buzby JC, Guthrie JF \& Kantor LS (2003) Evaluation of the USDA Fruit and Vegetables Pilot Program: Report to Congress. Washington, DC: Economic Research Service/USDA.

10. Bere E, Veierod MB, Bjelland M, et al. (2006) Free school fruit - sustained effect 1 year later. Health Educ Res 21, 268-275.

11. Bere E, Veierod MB, Skare O, et al. (2007) Free school fruit sustained effect three years later. Int J Behav Nutr Phys Act 4, 5.

12. Eriksen K, Haraldsdottir J, Pederson R, et al. (2003) Effect of a fruit and vegetable subscription in Danish schools. Public Health Nutr 6, 57-63.

13. Commission of the European Communities (2008) Proposal for a Council Regulation amending Regulations (EC) no 1290/2005 on the financing of the common agricultural policy and (EC) no $1234 / 2007$ establishing a common organisation of agricultural markets and on specific provisions for certain agricultural products (Single CMO Regulation) in order to set up a school fruit scheme 2008/0146 (CNS), Brussels

14. The Keystone Center (2006) The Keystone Forum on AwayFrom-Home Foods: Opportunities for Preventing Weight Gain and Obesity. Washington, DC: The Keystone Center.

15. Lachat CK, Huybregts LF, Roberfroid DA, et al. (2009) Nutritional profile of foods offered and consumed in a Belgian university canteen. Public Health Nutr 12, 122-128.

16. Lassen A, Thorsen AV, Trolle E, et al. (2004) Successful strategies to increase the consumption of fruits and vegetables: results from the Danish ' 6 a day' Work-site Canteen Model Study. Public Health Nutr 7, 263-270.

17. Roos E, Sarlio-Lahteenkorva S \& Lallukka T (2004) Having lunch at a staff canteen is associated with recommended food habits. Public Health Nutr 7, 53-61.

18. Faul F, Erdfelder E, Lang AG, et al. (2007) G*Power 3: a flexible statistical power analysis program for the social, behavioral, and biomedical sciences. Behav Res Methods 39, 175-191.
19. Willett WC (1998) Nutritional Epidemiology. New York: Oxford University Press.

20. Ainsworth BE, Haskell WL, Whitt MC, et al. (2000) Compendium of physical activities: an update of activity codes and MET intensities. Med Sci Sports Exerc 32, S498-S516.

21. Koebnick C, Wagner K, Thielecke F, et al. (2005) Validation of a simplified physical activity record by doubly labeled water technique. Int J Obes 29, 302-309.

22. Hoge Gezondheidsraad (Superior Health Council) (2005) Maten en Gewichten. Handleiding voor een gestandaardiseerde kwantificering van voedingsmiddelen (Measures and Weights: Manual for Standardised Quantification of Foods). Brussels: Hoge Gezondheidsraad.

23. Kirk RS \& Sawyer R (1990) Pearson's Composition and Analysis of Foods, 9th ed. Harlow, Essex: Longman Scientific and Technical.

24. AOAC (1990) Official Methods of Analysis of The Association of Official Analytical Chemists, 15th ed. Arlington, VA: Association of Official Analytical Chemists.

25. Zou ML, Moughan PJ, Awati A, et al. (2007) Accuracy of the Atwater factors and related food energy conversion factors with low-fat, high-fiber diets when energy intake is reduced spontaneously. Am J Clin Nutr 86, 1649-1656.

26. Nubel, De Belgische voedingsmiddelentabel (The Belgian Food Composition Table). Brussels: Ministry of Health (in Dutch).

27. VZW NUBEL (2006) The Belgian food composition table: database of trade names. www.internubel.be (accessed September 2007).

28. World Cancer Research Fund (1997) Food, Nutrition and The Prevention of Cancer: A Global Perspective. Washington: American Institute for Cancer Research.

29. Belgische hoge gezondheidsraad (Superior Health Council) (2006) Voedingsaanbevelingen voor Belgie, hierziene versie (Dietary Guidelines for Belgium: Revised Version). Brussels: Hoge Gezondheidsraad.

30. French SA \& Stables G (2003) Environmental interventions to promote vegetable and fruit consumption among youth in school settings. Prev Med 37, 593-610.

31. Sorensen G, Linnan L \& Hunt MK (2004) Worksite-based research and initiatives to increase fruit and vegetable consumption. Prev Med 39, S94-S100. 